\title{
LA DETERMINACIÓN DE LA LEY APLICABLE EN LOS REGLAMENTOS EN MATERIA DE RÉGIMEN ECONÓMICO MATRIMONIAL Y EFECTOS PATRIMONIALES DE LAS UNIONES REGISTRADAS 2016/1103 Y 2016/1104
}

\author{
Guillermo Palao Moreno*
}

SUMARIO: 1 . CUESTIONES INTRODUCTORIAS.-1.1. Contexto conflictual en el que surgen los Reglamentos y objetivos que persiguen.-1.2. Una tramitación dilatada y dos Reglamentos completos con propuestas «casi» paralelas.-1.3. Objeto del estudio, ámbito de aplicación de los Reglamentos y su incidencia en el sector de la ley aplicable.-2. EL JUEGO DE LA AUTONOMÍA DE LA VOLUNTAD.-2.1. Una electio iuris limitada.-2.2. La validez material y formal de la elección de ley aplicable y de las capitulaciones matrimoniales.-3. LEY APLICABLE EN DEFECTO DE ELECCIÓN.- 4. ÁMBITO DE LA LEY RECTORA Y TUTELA DE LOS INTERESES DE TERCEROS.-5. NORMAS DE APLICACIÓN.-5.1. Adaptación de los derechos reales, leyes de policía, orden público y exclusión del reenvío.- 5.2. Conflictos territoriales e interpersonales de leyes.-6. A MODO DE CONCLUSIÓN.

\section{CUESTIONES INTRODUCTORIAS}

1. Las instituciones europeas han dado un significativo paso adelante, en la conformación de un Derecho internacional privado (DIPr) de familia y sucesiones, con la aprobación del Reglamento (UE) núm. 2016/1103, del Consejo, de 24 de junio, por el que se establece una cooperación reforzada en el ámbito de la competencia, la ley aplicable, el reconocimiento y la ejecución de resoluciones en materia de regímenes económicos matrimoniales, y del Reglamento (UE) núm. 2016/1104, del Consejo, de la misma fecha, por el que se establece una cooperación reforzada en el ámbito de la competencia, la ley aplicable, el reconocimiento y la ejecución de resoluciones en materia de efectos patrimoniales de las uniones registradas ${ }^{1}$.

\footnotetext{
* Catedrático de Derecho internacional privado, Universitat de València. E-mail: Guillermo.palao@uv.es.

1 Ambos publicados en el Diario Oficial de la Unión Europea (DO) núm. L 183, de 8 de julio de 2016; corrección de errores DO núm. L 113, de 29 de abril de 2017.
} 


\subsection{Contexto conflictual en el que surgen los Reglamentos y objetivos que persiguen}

2. Los Reglamentos $2016 / 1103$ y 2016/1104 se vienen a sumar a los distintos hitos que, con fuerza renovada desde inicios del presente siglo, han ido jalonando la política de cooperación judicial en asuntos civiles con repercusión transfronteriza de la $\mathrm{UE}^{2}$. Y ello, en particular y con respecto al ámbito del DIPr de familia y sucesiones, con el objetivo de favorecer la libre circulación de las personas, en el espacio de libertad, seguridad y justicia europeo ${ }^{3}$. Un espacio donde se aprecia en la actualidad, un aumento en la movilidad de las personas y el incremento de parejas mixtas, en un contexto normativo caracterizado por las significativas diferencias existentes en la gestión legal que merecen tales instituciones, desde los sistemas normativos (tanto sustantiva, como internacional-privatista) de los Estados miembros de la UE ${ }^{4}$.

Esta diversidad se pone de manifiesto, de modo particular, no ya en relación con la institución matrimonial y los efectos económicos que de la misma se coligen, sino al respecto de las uniones registradas y su dimensión patrimonial. Una forma de unión que, ni tan siquiera cuenta con una legislación propia que la ordene en todos los Estados miembros y, en caso de existir tal normativa, resultan notables las diferencias existentes entre los distintos modelos nacionales en el marco de la Unión Europea ${ }^{5}$. El caso español resulta singularmente llamativo y perturbador al respecto. Y ello, debido a que España carece actualmente de un marco normativo - ya se trate de supuestos internos o internacionales-, no solo al respecto de las uniones registradas, sino con carácter general al respecto de las relaciones more uxuorio ${ }^{6}$. Y ello,

2 En este sentido, el Reglamento 2201/2003, relativo a la competencia, el reconocimiento y la ejecución de resoluciones judiciales en materia matrimonial y de responsabilidad parental (DO L 338, de 23 de diciembre de 2003; corrección de errores DO L 82, de 22 de marzo de 2013); Reglamento 4/2009, relativo a la competencia, la ley aplicable, el reconocimiento y la ejecución de resoluciones y la cooperación en materia de alimentos ( $D O \mathrm{~L} 7$, de 10 de enero de 2009; corrección de errores $D O \mathrm{~L} 131$, de 18 de mayo de 2011); Reglamento 1259/2010, por el que se establece una cooperación reforzada en el ámbito de la ley aplicable al divorcio y a la separación judicial ( $D O$ L 343, de 29 de diciembre de 2010); Reglamento 650/2012, relativo a la competencia, la ley aplicable, el reconocimiento y la ejecución de las resoluciones, a la aceptación y la ejecución de los documentos públicos en materia de sucesiones mortis causa y a la creación de un certificado sucesorio europeo (DO L 201, de 27 de julio de 2012).

3 También, Fernández Rozas, J. C., «Un hito más en la comunitarización del Derecho Internacional privado: regímenes económicos matrimoniales y efectos patrimoniales de las uniones registradas», La Ley Unión Europea, 2016, núm. 40, pp. 1-21, esp. p. 5.

4 Un amplio análisis comparativo en QuINZÁ REDONDo, P., Régimen económico matrimonial, Valencia, Tirant lo Blanch, 2016, pp. 39-166. Desde la conflictual, en concreto, el Étude sur les régimes matrimoniaux des couples mariés et sur le patrimoine des couples non mariés dans le droit international privé et le droit interne des etats membres de l'union européenne (accesible en http:/lec.europa.eu/civiljusticel publications/docs/regimes/report_regimes_030703_fr.pdf).

5 En cuyo caso no les obligaría el Reglamento, según el considerando 17.

"SÁnchez Lorenzo, S., "Las parejas no casadas ante el Derecho Internacional privado», REDI, 1989-2, XLI, pp. 487-531. Sobre sus efectos patrimoniales, CEBRIÁN SALVAT, M. A., «Los efectos patrimoniales de las parejas no registradas en Derecho Internacional privado español», $C D T$, vol. 10, 2018, núm. 1, pp. 127-143, esp. p. 138 (disponible en www.uc3m.es/cdt). Favorable a un tratamiento conflictual unitario de estas relaciones, FonTanellas Morell, J. M., «La ley aplicable a los regímenes 
a diferencia de la legislación prevista en las CCAA, aunque empleando una distinta terminología, así como con un dispar contenido y alcance ${ }^{7}$.

\subsection{Una tramitación dilatada y dos Reglamentos completos con propuestas "casi» paralelas}

3. La tramitación de los Reglamentos 2016/1103 y 2016/1104 ha distado de ser sencilla y expeditiva ${ }^{8}$. Así las cosas, encontramos precedentes a la voluntad de dotar a esta materia de una regulación uniforme en la UE en el Plan de Acción de Viena de $1998^{9}$, con reiteraciones en diversos Programas y Proyectos posteriores ${ }^{10}$. Sin embargo, su impulso más relevante se situó en la publicación del «Libro Verde sobre el conflicto de leyes en materia de regímenes económicos matrimoniales, con especial referencia a las cuestiones de competencia y reconocimiento mutuo» de $2006^{11}$, resultando decisiva la publicación en 2011, de sendas Propuestas de Reglamento del Consejo sobre los aspectos ius-internacional privatistas relacionados con el régimen matrimonial y los efectos económicos de las uniones registradas ${ }^{12}$.

El proceso legislativo que condujo a la publicación de los Reglamentos 2016/1103 y 2016/1004 ha resultado particularmente largo y complejo, así como se ha llevado a cabo de forma paralela al respecto de sendos instrumentos. Una dilación que puede encontrar su lógica explicación, entre otros, en la gran divergencia legislativa mencionada, la reticencia que algunos Estados miembros mantienen sobre las uniones del mismo sexo ${ }^{13}$, al igual que la dificultad que ha implicado la necesaria tramitación como un paquete de ambos Reglamentos (como también resultaría precisa una vinculación conjunta, en el caso de nuevas incorporaciones tras su aprobación) ${ }^{14}$. Motivos que habrían

económicos matrimoniales y a los efectos patrimoniales de las uniones registradas en las respectivas propuestas de reglamentación comunitaria», ADC, 2012, LXV, pp. 275-291, esp. pp. 287-288.

7 Todas las CCAA cuentan con alguna normativa relativa a parejas no casadas, ya sea al respecto de sus aspectos sustantivos o administrativos, siendo la más reciente incorporación la de la Región de Murcia (Ley 7/2018, en BOE núm. 183, de 30 de julio de 2018). Véase Soto MoYA, M., «El Reglamento (UE) 2016/1104 sobre régimen patrimonial de las parejas registradas: algunas cuestiones controvertidas de su puesta en funcionamiento en el sistema español de Derecho Internacional privado», REEI, 2018, pp. 1-32, esp. pp. 19-20.

8 Мота, H., «La armonización de la ley aplicable a los regímenes matrimoniales en la Unión Europea. The long and winding road», en GuZMÁn ZAPATER, M. y EsPlugues Mota, C. (dirs.), Persona y familia en el nuevo modelo de Derecho Internacional privado, Valencia, Tirant lo Blanch, 2017, pp. 273-284, esp. pp. 273-276.

9 DO C 19, de 23 de enero de 1999.

10 Así, los Programas de La Haya de 2004 [COM (2005) 184] o de Estocolmo de 2009 (DO C 115 , de 4 de mayo de 2010).

11 COM (2006) 400 final.

12 COM (2011) 126 final y COM (2011) 127 final.

13 Como sucede con Hungría y Polonia. Crítico, Lagarde, P., «Règlements 2016/1103 et 2016/1104 du 24 juin 2016 sur les régimes matrimoniaux et sur le régime patrimoniaux des partenariats enregistrés», Riv. dir. int. pr. proc., 2016.3, pp. 676-686, esp. pp. 676-677.

14 Una tramitación conjunta que se justificó, entre otros, por el apoyo que implicaba para la continuidad del Reglamento sobre uniones registradas. CARRIÓN GARCía DE PARADA, P., «El proyecto de Reglamento Europeo sobre regímenes matrimoniales», $A M N, 2013$, LIV, pp. 77-150, esp. p. 108. 
justificado la falta de unanimidad en su adopción —como prevé el art. 81.3 TFUE para este ámbito-, y el recurso al procedimiento de cooperación reforzada, finalizando con su aprobación por parte de dieciocho Estados miembros (entre ellos, España) ${ }^{15}$.

4. Junto a lo expuesto, ambos instrumentos se caracterizan por constituirse como Reglamentos «completos», al regular de modo uniforme los tres sectores principales del DIPr al respecto de las cuestiones que cubren, para los Estados participantes en la cooperación reforzada ${ }^{16}$; siguiendo así la estela e inspiración de instrumentos como el Reglamento 650/2012 ${ }^{17}$. En esta línea y con base jurídica en el art. 81 TFUE, cuentan entre sus propósitos principales, el mantener y desarrollar un espacio de libertad, seguridad y justicia donde se garantice la libre circulación de las personas (considerando 1), así como garantizar la seguridad jurídica de las parejas casadas y miembros de una unión registrada donde se les ofrezca un cierto nivel de previsibilidad (considerando 15).

Por todo ello, los sistemas autónomos de DIPr de los Estados participantes en la cooperación reforzada van a quedar profundamente modificados, a partir del 29 de enero de 2019, cuando estos instrumentos resulten plenamente aplicables (en atención a lo previsto en su art. 70). Más aún, si se tiene en consideración la aplicación universal de sus soluciones, tanto al respecto de las normas de competencia judicial internacional —según contempla su art. 15-, como de la determinación de la ley aplicable (así, la literalidad del art. 20, como resulta tradicional en los instrumentos europeos que contemplan soluciones conflictuales) - jugando las relativas a la circulación de resoluciones, documentos públicos y transacciones judiciales, únicamente Estado a Estado-.

\subsection{Objeto del estudio, ámbito de aplicación de los Reglamentos y su incidencia en el sector de la ley aplicable}

5. El presente trabajo se enfrenta exclusivamente a los aspectos conflictuales de los Reglamentos 2016/1103 y 2016/1104 (desarrollados en su Capítulo III, arts. 20 a 35). Unos preceptos que se alinean con los objetivos generales de favorecer la seguridad jurídica y la previsibilidad - tanto para las partes, como los terceros- ${ }^{18}$. En este sentido, y a pesar de su innegable importancia, se excluyen de este estudio el resto de sectores que incorporan. Un análisis que, debido a la estrecha relación y tramitación en paralelo de

\footnotetext{
15 Suecia, Alemania, Austria, Bélgica, Bulgaria, Chipre, Croacia, Eslovenia, España, Finlandia, Francia, Grecia, Italia, Luxemburgo, Malta, Países Bajos, Portugal y República Checa.

${ }_{16}$ Mientras el Capítulo II se refiere a la competencia judicial internacional, el Capítulo III a la determinación de la ley aplicable, el Capítulo IV a la aceptación, la fuerza ejecutiva y la ejecución de resoluciones, y el Capítulo $\mathrm{V}$ a los documentos públicos y transacciones judiciales.

17 Lagarde, P., op. cit., p. 677.

18 MartinY, D., «Die anknüpfung güterrrechtlicher Angelegenheiten nach den Europäischen Güterrechtsverordnungen», $Z f P W, 2017,1,1-33$, p. 13, considerando 43.
} 
tales instrumentos europeos, así como por sus similitudes, se llevará a cabo de forma conjunta y empleando principalmente el relativo a los regímenes económicos matrimoniales - para evitar duplicidades y reiteraciones farragosas-; consignando puntualmente las diferencias que podría guardar el consagrado a los efectos patrimoniales de las uniones registradas con respecto al otro.

De esta forma y de modo inicial, junto a la pluralidad regulatoria ya señalada (en este caso, desde el sector de la ley aplicable), hay que destacar la incidencia que han ejercido en la elaboración de las normas del Capítulo III, diversos instrumentos normativos. Tal y como se aprecia, tanto en el Convenio de La Haya de 1978 sobre Ley Aplicable a los Regímenes matrimoniales - aplicable tan solo, por lo que respecta a la UE, en Francia, Luxemburgo y los Países Bajos- ${ }^{19}$, como en las respuestas conflictuales que ofrecen otros instrumentos europeos precedentes —como los Reglamentos 1259/2010 y $650 / 2012$, igualmente tramitado, el primero de ellos, por medio de un procedimiento de cooperación reforzada- ${ }^{20}$.

6. No obstante, aunque sin la intención de analizar con profundidad las cuestiones que suscita la concreción del ámbito de aplicación de los Reglamentos analizados —ordenadas, de manera principal, en su Capítulo I-, resulta necesario hacer mención previa a esta significativa cuestión, por la incidencia que va a poseer en las soluciones conflictuales previstas en los sistemas estatales de DIPr. Una operación que se realizará estrictamente a tales efectos, distinguiendo entre la delimitación de su ámbito de aplicación material y el de naturaleza territorial.

7. De un lado y por lo que hace a su ámbito de aplicación material, el art. 1 se refiere a las materias incluidas y a aquellas excluidas (según el modelo seguido por el resto de Reglamentos en materia de cooperación judicial civil), el art. 2 confirma la competencia de los Estados miembros al respecto de la dimensión sustantiva de las relaciones que se encuentran cubiertas (al ocuparse únicamente de los aspectos internacional-privatistas), y el art. 3 incorpora una serie de definiciones de gran interés para la aplicación uniforme de los Reglamentos ${ }^{21}$.

A tenor del art. 1 -y subraya el considerando 18-, los Reglamentos se ocupan, desde una perspectiva positiva, de la ordenación de los efectos económicos de los matrimonios («régimen económico matrimonial») y de las uniones registradas («efectos patrimoniales de las uniones registradas») —afectando tanto su administración cotidiana, como su liquidación—en su-

19 Accesible en https://www.hcch.net/es/instruments/conventions/full-text/?cid=87.

20 LAgarde, P., op. cit., p. 681. Un reiterado recurso a la cooperación reforzada en materia de familia que ha derivado en una auténtica «Europa a la carta» (FERNÁNDEZ RozAS, J. C., op. cit., p. 14), que dificulta la uniformidad y lo convierte en un verdadero puzle [MARINO, S., «Strengthening the European Civil judicial Cooperation: the Patrimonial Effects of Family Relationships», CDT, vol. 9, 2017, núm. 1, pp. 265-284, esp. p. 284 (disponible en www.uc3m.es/cdt)].

${ }_{21}$ La cual habrá de complementarse con la concreción del ámbito de la lex causae que se ordena en el art. 27 (infra apdo. 4). 
puestos de naturaleza transfronteriza. Por motivos de claridad ${ }^{22}$, y desde un punto de vista negativo, el art. 1 contempla igualmente la exclusión (además de las tradicional mención de los aspectos fiscales, aduaneros y administrativas) de ciertos extremos de la importancia de la capacidad jurídica de las partes o de cuestiones preliminares como la propia existencia de esta relación - considerandos 20 y 21-; junto a otras materias como serían las cuestiones cubiertas por otros Reglamentos ${ }^{23}$, al igual que otro ámbitos ajenos pero relacionados (como la seguridad social o las consecuencias derivadas de la anulación o disolución de la relación), así como la ya recurrente exclusión de los derechos reales y su inscripción —entendida de forma estricta— ${ }^{24}$.

Esta concreción - tanto positiva, como negativa - se ve acompañada, en su art. 3, de una serie de definiciones de una gran utilidad. Entre ellas destaca, para empezar, la lógica ausencia de una delimitación uniforme de «matrimonio», frente a una bienvenida definición autónoma y uniforme de «unión registrada» - con exclusión de otras uniones que carezcan de este grado de institucionalización- ${ }^{25}$. No obstante, en este último caso, hay que tener en cuenta de que se trata de una noción válida únicamente a los efectos de la aplicación del Reglamento 2016/1104 — con independencia de los conceptos que pudieran emplearse en otros instrumentos europeos-, siendo que su contenido real y material se situará en los Derechos estatales ${ }^{26}$. Podría así

${ }^{22}$ Aunque de forma matizada, al respecto de las facultades y los derechos sobre su patrimonio, según el considerando 19.

23 Destacando, según el considerando 22, ámbitos como las obligaciones de alimentos (Reglamento $4 / 2009$ ) o las sucesiones (Reglamento 650/2012).

${ }^{24}$ Sobre las consecuencias que se derivan de esta exclusión (considerandos 27 y 28), PEITEADO MARISCAL, P., "Competencia internacional por conexión en materia de régimen económico matrimonial y de efectos patrimoniales de uniones registradas. Relación entre los Reglamentos UE 2201/2003, 650/2012, 1103/2016 y 1104/2016», CDT, vol. 9, 2017, núm. 1, pp. 300-326, esp. p. 308 (disponible en www.uc3m.es/cdt). En virtud de su considerando 23, se regularán: «La clasificación de los activos de pensiones, los importes que ya se hayan abonado a uno de los cónyuges (miembros de la unión registrada) durante la relación y la compensación en caso de pensiones suscritas con bienes comunes».

25 Fontanellas Morell, J. M., «Una primera lectura de las propuestas de Reglamento comunitario en materia de regímenes económico matrimoniales y de efectos patrimoniales de las uniones registradas», en PARra, C. (dir.), Nuevos Reglamentos comunitarios y su impacto en el Derecho catalán, Barcelona, Bosch, 2013, pp. 257-290, esp. pp. 262-263; GonzÁlez BeIlfuss, C., «The Proposal for a Council Regulation on the Property Consequences of Registatred Partnerships», YbPIL, 2011, núm. 13, pp. 183198, esp. pp. 184-185. Al respecto de los límites de esta definición, DutTA, A., «Matrimonial property regimes in European Private International Law. Beyond husband and wife - New couples' regimes and the European property regulations», YbPIL, 2017-2018, pp. 145-158, esp. pp. 146-148 y 157. Sobre los distintos modelos de «uniones» que coexisten en los Estados miembros de la UE, Boele-WoelKI, K., Mol, V. y VAN Gelder, E. (eds.), European Family Law in action. vol. V. Informal relationships, Cambrigde, Intersentia, 2015; MILES, J., «Unmarried cohabitation in a European perspective», en SCHERPE, J. M. (ed.), European Family Law, vol. III, Chetenham, Edward Elgar, 2014, pp. 82-115.

26 Aun cuando el considerando 16 del Reglamento 2014/110 obliga a diferenciar entre uniones de hecho y las que cuentan con un registro, en el 17 se aclara que el instrumento no impone obligación alguna para la normativa de aquellos Estados miembros que, como España, «no contemple la institución de la unión registrada a establecer dicha institución en su Derecho nacional». Véanse AÑoveros TERRADAS, B., «Autonomía de la voluntad conflictual y sus límites en los nuevos Reglamentos comunitarios en materia de regímenes económicos matrimoniales y efectos patrimoniales de las uniones registradas", en Guzmán Zapater, M. y Esplugues Mota, C. (dirs.), op. cit., pp. 241-272, esp. p. 249; Cebrián Salvat, M. A., op. cit., pp. 140-142; VARGAS GómEZ-UrRUTIA, M., "El puzle se complica. Efectos patrimoniales 
estimarse que este precepto incorporaría, por tanto, una suerte de norma de conflicto implícita a partir de la que se garantizaría el reconocimiento de las relaciones válidamente constituidas en otro Estado miembro ${ }^{27}$, aunque no desde una perspectiva material; sino que únicamente como si se tratara de un hecho ${ }^{28}$.

En este sentido, se ha optado por una aproximación respetuosa con la tradición normativa de los Estados miembros, aunque susceptible de generar problemas de aplicación en la práctica, en atención de las disparidades estatales existentes en la actualidad en su delimitación ${ }^{29}$. En el caso español, ante la ausencia de normativa a nivel estatal que las regule, se plantearía la cuestión previa relativa a determinar qué tipo de «uniones» - de las contempladas por la normativa de las CCAA-, entrarían en el concepto que ofrece el Reglamento 2016/1104 ${ }^{30}$. Asimismo, los Reglamentos incorporan definiciones de términos de la importancia de «régimen económico matrimonial», «efectos patrimoniales de la unión registrada» o "capitulaciones» - ya se trate de matrimoniales o de la unión registrada- ${ }^{31}$, que podrán minimizar los problemas calificatorios que pudieran originarse en su aplicación práctica ${ }^{32}$.

8. Desde una perspectiva territorial, los Reglamentos resultan de plena aplicación para España, en tanto que Estado miembro participante en el proceso de cooperación reforzada. Una aplicación que está llamada a desplazar las normas de conflicto de leyes previstas en los ordenamientos de los Estados participantes en este procedimiento, debido a su carácter erga omnes —consagrado en el art. 20_. A su vez, igualmente desde una óptica espacial

de las uniones registradas y Reglamento (UE) 2016/1104. Problemas de calificación y coordinación entre los instrumentos europeos conexos", en GuzMÁn ZaPATER, M. y EsPlugues Mota, C. (dirs.), op. cit., pp. 313-328, esp. p. 328.

27 VinAIXA Miquel, M., «La autonomía de la voluntad en los recientes reglamentos UE en materia de regímenes económicos matrimoniales (2016/1103) y efectos patrimoniales de las uniones registradas (2016/1104)», InDret, 2017, pp. 274-313, esp. pp. 282-283 (disponible en www.indret.com).

28 MARINO, S., op. cit., p. 269.

29 Peiteado Mariscal, P., op. cit., p. 306; Rodríguez Pineau, E., «Los efectos patrimoniales de las uniones registradas: algunas consideraciones sobre la propuesta de reglamento del Consejo", $A E D I P r$, t. XI, 2011, pp. 937-955, esp. pp. 944-945.

30 Marín Consarnau, D., "Las “uniones registradas” en España como beneficiaria del derecho de la UE a propósito de la Directiva 2004/38/CE y del Reglamento (UE) 2016/1104», CDT, vol. 9, 2017, núm. 2, pp. 419-447, esp. pp. 442-445 (accesible en https://e-revistas.uc3m.es/index.php/CDT/article/ view/3880); QuiÑones EscámEZ, A., «Nuevos tipos de uniones y nueva regulación de sus efectos», en Guzmán Zapater, M. y Esplugues Mota, C. (dirs.), op. cit., pp. 169-187, esp. pp. 170-173 y 182-186; Soto Moya, M., op. cit., pp. 20-22; VARgas Gómez-URrutia, M., op. cit., pp. 316-318.

31 Incluyendo el régimen económico primario y el secundario, aunque tenga que delimitarse de forma autónoma. DAMAScElli, D., «La legge applicabile ai raporti patrimoniali tra coniugi, unite civilmente e conviventi di fatto nel diritto internazionale privato ed europeo", Riv. dir. int., 2017, núm. 4, pp. 1103-1155, esp. p. 1136; PÉROz, H., «Le noveau règlement européen sur les régimes matrimoniaux», La Semaine Juridique Notariale et Immobilière, 2016, núm. 29, pp. 33-39, esp. p. 38.

32 Sobre los problemas calificatorios que se pueden manifestar al respecto de las «capitulaciones» y las diferencias entre los matrimonios y las uniones registradas, AÑOVEROS TERRADAS, B., «El régimen conflictual de las capitulaciones en los nuevos Reglamentos de la Unión Europea en materia de regímenes económicos matrimoniales y efectos patrimoniales de las uniones registradas», $A E D I P r$, t. XVII, 2017, pp. 821-845, esp. pp. 828-830. 
—aunque sin incidencia alguna para nuestro país_-, el art. 62 contempla que tales Reglamentos no afectarán a los Convenios vigentes, salvo aquellos entre Estados miembros, prevaleciendo sobre los mismos. Una mención que, desde la dimensión de la ley aplicable, se refiere principalmente al Convenio de La Haya de 1978, que continuará aplicándose en Francia, Holanda y Luxemburgo, así como los Convenios que sobre esta materia han suscritos los países escandinavos.

9. De esta sucinta exposición del ámbito de aplicación de los Reglamentos se deriva, para un sistema autónomo de DIPr como el español ${ }^{33}$, de una parte, el desplazamiento de nuestros arts. 9.2 y $9.3 \mathrm{CC}$-así como el 11, por lo que respecta a los aspectos formales- ${ }^{34}$. Aunque habría que matizar esta afirmación, debido a que, mientras la determinación de la ley aplicable a los efectos personales del matrimonio se continuará regulando por lo establecido en el art. 9.2 CC, serán las soluciones previstas en estos instrumentos europeos quienes, de forma exclusiva, ordenen los supuestos relativos a los efectos patrimoniales del matrimonio. Asimismo, hay que tener presente que los numerales 2 y 3 del art. 9 CC continuarán resultando operativos al respecto del ámbito interregional español ${ }^{35}$.

Junto a ello, por otra parte, se incorporan a nuestro ordenamiento nuevas normas de conflicto uniformes relativas a los efectos patrimoniales de las uniones registradas; unas relaciones ignoradas hasta la fecha en nuestro sistema de DIPr. Asimismo, y vinculado con esta cuestión, la existencia y validez tanto del matrimonio, como de las uniones registradas -incluida la cuestión de la admisibilidad de que las mismas se hubieran celebrado entre personas del mismo sexo- ${ }^{36}$, seguirán viéndose reguladas por lo previsto por nuestro sistema de DIPr, al encontrarse fuera del ámbito de aplicación de los Reglamentos. En este sentido, continuará vigente el art. 9.1 CC, al respecto de la determinación de la ley rectora de la capacidad de los cónyuges y de los miembros de la unión registrada ${ }^{37}$.

En otro orden de ideas, ambos instrumentos parten -en su art. 21-, del principio de unidad de la ley aplicable. En virtud del cual, tales efectos se ordenarán por medio de un único ordenamiento estatal, con independencia de la naturaleza de los bienes y de su ubicación, evitando el la escisión o fraccionamiento de su regulación ${ }^{38}$. Un principio que, además de servir a los objetivos de certeza legal y previsibilidad, cuenta con un carácter tradicional para un significativo número de Estados miembros de la UE —como Espa-

33 Un completo estudio de la incidencia y las necesarias adaptaciones que suscitan en relación con sistemas como el alemán, HeIDERHOFF, B., «Vorschläge zur Duirchführung der EU-Güterrechtsverordungen», IPRax, 2017, núm. 3, pp. 231-238.

34 AÑoveros Terradas, B., "Autonomía de la voluntad...», op. cit., p. 253; VinAiXA Miquel, op. cit., p. 290.

35 Infra, apdo. 5.2

36 DAmascelli, D., «La legge applicabile...», op. cit., p. 1136.

37 Véase Diago Diago, P., Pactos o capitulaciones matrimoniales en Derecho Internacional privado español, Zaragoza, El Justicia de Aragón, 1999, pp. 77-79.

38 FERnández Rozas, J. C., op. cit., p. 12. 
ña- ${ }^{39}$. No obstante, hay que tener presente que este principio choca con la tradición de fraccionamiento presente en algunos Estados miembros ${ }^{40}$. Además, y como acertadamente se ha puesto de manifiesto, esta opción -a pesar de sus bondades- puede generar problemas de coordinación con la lex rei sitae - en relación, por ejemplo, con supuestos de sucesión- al respecto de aquellas cuestiones relativas a la propiedad, los derechos reales y su publicidad ${ }^{41}$.

\section{EL JUEGO DE LA AUTONOMÍA DE LA VOLUNTAD}

10. La autonomía de la voluntad constituye, hoy por hoy, un principio regulador con una rápida y profunda penetración y extensión en el DIPr europeo de familia y sucesiones ${ }^{42}$. En relación con la materia analizada, destaca como el principio autonomista ha contado tradicionalmente con una significativa presencia - desde una perspectiva comparada y convencional-, en el ámbito de la determinación de la ley aplicable a los efectos patrimoniales del matrimonio ${ }^{43}$. Y ello, al respecto de poder seleccionar tanto la ley aplicable

39 Quinzá Redondo, P., «La unificación — fragmentada- del Derecho Internacional privado de la Unión Europea en materia de régimen económico matrimonial: el Reglamento 2016/1103», RGDE, 2017, núm. 41, pp. 180-222, esp. p. 202; RodRíGUEZ BENOT, A., «La armonización del régimen económico matrimonial en la Unión Europea: la propuesta de Reglamento de marzo de 2011 », en EsPLUGUES Mota, C. y Palao Moreno, G. (eds.), Nuevas fronteras del Derecho de la Unión Europea. Liber amicorum José Luis Iglesias Buhigues, Valencia, Tirant lo Blanch, 2012, pp. 555-571, esp. p. 566; RodRíGUEz PINEAU, E., Régimen económico matrimonial. Aspectos internacionales, Granada, Comares, 2002, pp. 6264. Este principio se encuentra presente, como solución de partida, en los arts. 3 y 6 del Convenio de La Haya de 1978, aunque matizado parar dar entrada igualmente a la lex rei sitae.

${ }^{40} \mathrm{Y}$ ello, tanto para los países obligados por el Convenio de La Haya de 1978, como al respecto de Estados miembros como Alemania. Véase DutTA, A., "Das neue internationale Güterrecht der Europäischen Union - ein Abriss der europäischen Güterrrechtsverordnungen», FamRZ, 2016, núm. 23, pp. 1973-1985, esp. p. 1980.

41 Martiny, D., op. cit., p. 13; Quinzá Redondo, P., «La unificación -fragmentada-...», op. cit., p. 202. En tales supuestos, cabría acudir a las excepciones presentes en previsiones relativas a la forma, protección de terceros o las normas de aplicación que se analizarán seguidamente, a juicio de CoESTERWALTJEN, D., "Connecting factors to determine the law applicable to matrimonial property regimes", YbPIL, 2017-2018, núm. 19, pp. 195-211, esp. p. 200.

${ }^{42}$ Entre otros, nuestro trabajo, "Crisis matrimoniales internacionales y autonomía de la voluntad», Cursos de Derecho Internacional y Relaciones Internacionales de Vitoria-Gasteiz, 2013, pp. 451-531, esp. pp. 457-459; AÑoveros TERRADAS, B., «La autonomía de la voluntad como principio rector de las normas de Derecho Internacional privado comunitario de familia», en ForNER DELAYGUA, J., GonZÁLEZ BeILfuss, C. y ViÑas FarRé, R. (coords.), Entre Bruselas y La Haya. Estudios sobre la unificación internacional y regional del Derecho Internacional privado. Liber amicorum Alegría Borrás, Madrid, Marcial Pons, 2013, pp. 119-131, esp. pp. 125-131; CARruthers, J., "Party Autonomy in the Legal Regulation of Adult Relationships: What Place for Party Choice in Private International Law», 61, ICLQ, 4, pp. 881913; Diago Diago, P., «El matrimonio y su crisis ante los nuevos retos de la autonomía de la voluntad conflictual», REDI, 2014-2, LXVI, pp. 49-79.

43 JAYME, E., «Identité culturelle et intégration: le droit international privé postmoderne», $R$ des $C$, t. 251,1995 , pp. 9-268, esp. p. 163. Un estudio comparativo sobre su plasmación y alcance, DiAGo DiAGo, P., Pactos o capitulaciones matrimoniales..., op. cit., pp. 179-192; VIARENGo, I., Autonomia della volontà e rapporti patrimoniali tra coniugi nel diritto internazionale privato, Padua, Cedam, 1996. Los beneficios de una opción limitada en estos supuestos de uniones registradas han sido destacados por Rodríguez Pineau, E., «Los efectos patrimoniales...», op. cit., pp. 950-952 y 955. 
estatal que los regule, como el régimen sustantivo que se prevea en dicha normativa estatal para ordenarlos, por medio de una capitulación en las que se opte por un régimen económico o así lo cree.

En consecuencia, la inclusión del principio autonomista en los Reglamentos 2016/1103 y 2016/1104 — como solución de partida—, ha de ser bienveni$\mathrm{da}^{44}$, al resultar plenamente coherente con la promoción de los intereses de las partes, la seguridad jurídica y la previsibilidad que informa estos instrumentos europeos -favoreciendo así su coordinación- ${ }^{45}$. No obstante, su juego no es absoluto y suele verse limitado en su concreción — principalmente desde una perspectiva conflictual-, con el fin de garantizar la existencia de conexión con la relación, así como para atender a los derechos y expectativas de terceros.

Resulta plenamente razonable, por tanto, que la posibilidad de elección de la ley aplicable en este ámbito cuente con una detallada regulación en los Reglamentos 2016/1103 y 2016/1104, que se despliega en su arts. 22 a $25^{46}$. De este modo, y como se desarrollará seguidamente, mientras que el art. 22 contempla la regla general relativa a la electio iuris, los arts. 23 y 25 se refieren respectivamente a la validez formal del acuerdo de ley, por lo que respecta a la concreción de la normativa rectora de la relación y al respecto de las capitulaciones matrimoniales, mientras que el art. 24 regula el consentimiento y la validez material de la elección de ley.

\subsection{Una electio iuris limitada}

11. En atención a lo establecido en el art. 22.1, los cónyuges o futuros cónyuges (o miembros de la unión registrada) podrán seleccionar o modificar de mutuo acuerdo la normativa estatal llamada a regir su régimen económico ${ }^{47}$. Nos encontraríamos, por tanto, ante la posibilidad de una elección expresa a favor de una determinada ley estatal, como solución de partida; sin contemplarse, empero - en línea de principio y en atención a la literalidad del precepto-, el juego de una sumisión tácita ${ }^{48}$. No obstante, dicha libertad

${ }^{44}$ Resultando una novedad para el ámbito de las uniones registradas, en relación con la propuesta de 2011. Rodríguez Pineau, E., «Los efectos patrimoniales...», op. cit., pp. 950-952.

45 Quinzá Redondo, P. y GRAY, J., «La (des) coordinación entre la propuesta de Reglamento de régimen económico matrimonial y los Reglamentos en materia de divorcio y sucesiones», AEDIPr, 2013, XIII, pp. 513-542, esp. pp. 535-540; VIARENGO, I., "The EU Proposal on matrimonial property regimes. Some general remarks», YbPIL, 2011, núm. 13, pp. 199-215, esp. p. 210; WAUTELET, P., «What's wrong with article 22? The unsolved mysteries of choice of law for matrimonial property», $Y b P I L, 2017-2018$, núm. 19, pp. 213-231, esp. pp. 216-218.

46 Los cuales, como señala el art. 68.3, únicamente cubrirán las situaciones que se susciten tras la plena aplicación de los Reglamentos, sin que quepa extender su eficacia a supuestos de professio iuris anteriores a esa fecha. WAUTELET, P., op. cit., pp. 225-226.

47 No cabrá referirse a «Principios» u a otras reglas, sino a las leyes de un país. AÑoveros TerRADAS, B., "Autonomía de la voluntad...», op. cit., p. 258.

${ }^{48}$ Una opción prevista en el art. 11 del Convenio de La Haya de 1978. Desde una perspectiva práctica, no puede negarse que la referencia a un cambio de régimen legal por medio de unas capitulaciones podría tener este efecto en determinadas circunstancias y de forma indirecta (МотА, Н., op. cit., p. 282; 
no se contempla de forma absoluta sino limitada - como resulta tradicional para esta materia-, debido a que únicamente podrán seleccionar alguna de las leyes estatales previstas en sus letras $a$ ) y $b$ ), con el objetivo de garantizar una cierta conexión entre la normativa estatal elegida por las partes y la relación subyacente ${ }^{49}$.

De este modo, y con un carácter alternativo, las partes podrán optar entre la aplicación de: o bien la ley del país de residencia habitual (común o de uno de ellos) en el momento de la celebración del acuerdo, o bien la del lugar de la nacionalidad de cualquiera de ellos, fijada en el mismo momento antes mencionado ${ }^{50}$. Una opción múltiple, a la que se habría que sumar como tercera alternativa abierta a las partes - aunque únicamente para el caso de la unión registrada-, ley estatal de conformidad a la cual se hubiera creado dicha relación - para garantizar la eficacia de su elección- ${ }^{51}$. Consecuentemente, a virtud del tenor de este precepto, se autorizaría a las partes a llevar a cabo esta selección de entre hasta cuatro ordenamientos estatales distintos (caso de que su nacionalidad y/o residencia habitual fuera distinta), pudiendo llegar incluso a seis ordenamientos (en supuestos de doble nacionalidad de las partes $)^{52}$, ofreciéndoles así una opción bastante generosa, que asimismo garantiza una conexión con la relación.

Esta orientación se encuentra, a su vez, inspirada en las soluciones previstas en otros Reglamentos anteriormente elaborados en materia de familia y sucesiones —arts. 5 del Reglamento 1259/2010 y 22 del Reglamento 650/2012 53 -, que avalarían su coordinación conflictual por medio del juego de la professio iuris ${ }^{54}$; contando asimismo con un claro precedente en el art. 3 del Convenio de La Haya de 1978.

Ahora bien y como se ha expuesto, en el caso de las uniones registradas se incorpora la alternativa del ordenamiento del lugar donde se creó. Una

WAUTELET, P., op. cit., p. 222), aunque la elección de un determinado régimen económico no podría entenderse directa y automáticamente como un supuesto de sumisión tácita (MARINO, S., op. cit., p. 279).

49 Considerandos 45 del Reglamento 2016/1103, y 44 del Reglamento 2016/1104. Diago Diago, P., «El matrimonio y su crisis...», op. cit., pp. 58-62; FonTANELlas MoRELL, J. M., «Una primera lectura...», op. cit., pp. $274-275$.

50 Con independencia de si se tratara de un nacional de un Estado miembro o de un tercer país. MARTINY, D., op. cit., p. 17.

51 AÑoveros TerRadAS, B., «Autonomía de la voluntad...», op. cit., p. 258.

$52 \mathrm{Y}$ ello, por no verse excluida esta posibilidad en la literalidad del precepto (como sí se hace en relación con el art. 26.2), como en apoyo de lo dispuesto para otros Reglamentos, como el art. 22.1.2 del Reglamento 650/2012 o el art. 5.c) del Reglamento 1259/2010. QuINZÁ REDONDO, P., «La unificación —fragmentada-...», op. cit., p. 204.

53 De forma respectiva, nuestros estudios: «La ley aplicable al divorcio. El Reglamento (UE) núm. 1259/2010, de 20 de noviembre (Roma III)», en Pereña Vicente, T. y Delgado Marín, P. (dirs.), Nuevas orientaciones del Derecho Civil en Europa, Madrid, Thomson Reuters/Aranzadi, 2015, pp. 661675, esp. pp. 664-668; y «Artículo 22. Elección de la ley aplicable», en IgLesias BuHigues, J. L. y PaLAO Moreno, G. (dirs.), Sucesiones internacionales. Comentarios al Reglamento (UE) 650/2012, Valencia, Tirant lo Blanch, 2015, pp. 151-160.

${ }^{54}$ Habría que tomar en cuenta la diferente plasmación de este principio para no malograr su coordinación. BonOMI, A., «The interaction among the future EU instruments on matrimonial property, registered partnership and successions», YbPIL, 2011, núm. 13, pp. 217-231, esp. p. 230. 
solución razonable, debido a la estrecha vinculación existente con la relación y por garantizar la elección de una ley que atribuya efectos patrimoniales a la unión ${ }^{55}$. Algo que nos permite cuestionar, sin embargo, el motivo por el que no se incorporó una conexión alternativa similar - como sería su lugar de celebración - para el caso de los matrimonios (presente, entre otros, en nuestro art. $9.3 \mathrm{CC})^{56}$.

12. El recurso prioritario a la residencia habitual y la nacionalidad como puntos de conexión, no debe causar sorpresa en relación con este singular ámbito, al resultar tradicionales en los instrumentos europeos en el ámbito del DIPr de familia y sucesiones ${ }^{57}$. Su incorporación permite establecer un equilibrio entre los objetivos de permitir una voluntaria integración jurídica de la relación en un determinado país y la defensa de la identidad cultural de las partes ${ }^{58}$. De ahí que, en línea de principio, haya que felicitar este loable propósito y su concreta plasmación en este precepto. Ahora bien, a pesar de sus bondades y de presentarse de modo usual en tales Reglamentos europeos, ha de censurarse que los instrumentos analizados no ofrecen una certeza legal plena en la formulación de las conexiones en las que se basa. En este sentido, los Reglamentos 2016/1103 y 2016/1104 no cuentan con una definición uniforme de los puntos de conexión «residencia habitual» $\mathrm{y}$ «nacionalidad» - como tampoco sus precedentes normativos-. Una postura que, aunque sensata y plenamente respetuosa en el actual contexto del DIPr de la UE, podría generar una cierta imprevisibilidad en la práctica a la hora de su delimitación autónoma.

Por lo que respecta a la residencia habitual, en particular, hay que tener presente que los riesgos de su petrificación y la necesidad de adaptar este criterio fáctico a las circunstancias del caso concreto, desaconsejaban elaborar una definición uniforme. No obstante, hubiera resultado conveniente incorporar alguna indicación que sirviera de guía práctica para su delimitación ${ }^{59}$, que según el criterio de un sector doctrinal podría pasar por valorar la efectiva

55 Considerandos 44 del Reglamento 2016/1103, y 43 del Reglamento 2016/1104. En todo caso, si dicho ordenamiento no otorgara tales efectos, se entenderá que la elección deviene inválida y no realizada. MARINO, S., op. cit., p. 277.

56 Quinzá Redondo, P., Régimen económico matrimonial, op. cit., pp. 178-179. Sobre los límites de criterio lex loci celebrationis del matrimonio en el contexto europeo, PERTEGÁs, M., «Beyond nationality and habitual residence: other connecting factors in European Private International Law in Family matters», en Meeusen, J., Pertegas, M., Straetmans, G. y Swennen, F. (eds.), International Familiy Law for the European Union, Amberes-Oxford, Intersentia, 2007, pp. 319-340, esp. pp. 326-328.

57 Sobre sus relaciones con los principios y libertades europeas, BogDAN, M., «The EC Treaty and the use of nationality and habitual residence as connecting factors in International Family Law», en Meeusen, J., Pertegas, M., Straetmans, G. y Swennen, F. (eds.), op. cit., pp. 303-317.

58 En otras palabras, la conexión "social», frente a la «cultural», como destacan QUINZÁ REDONDO, P. y GraY, J., op. cit., p. 531. Por lo que hace a la segunda, con independencia de si se tratara de una nacionalidad de un Estado miembro o no, PÉroz, H., op. cit., p. 36. Con carácter general, CARLIER, J.-Y., «Estatuto personal y sociedad multicultural: el papel de la autonomía de la voluntad», en CALVo CARAVACA, A. L. e IRIARTE ÁNGEL, J. L. (eds.), Estatuto personal y multiculturalidad de la familia, Madrid, Colex, 2000, pp. 27-38, esp. pp. 35-36; Bucher, A., "La familie en droit international privé», $R$ des $C$, t. 283,2000 , pp. $9-186$, esp. pp. 90-91.

59 Como sí hace el Reglamento 650/2012, en sus considerandos 23 a 25. 
integración social del sujeto en un determinado territorio ${ }^{60}$. A este respecto, resulta de interés la aproximación jurisprudencial que se ha producido en el contexto del Reglamento $2201 / 2003^{61}$. Una jurisprudencia que, aunque difícilmente aplicable de forma directa a estos supuestos por las diferencias que los separan, podría servir de inspiración y favorecería la certeza y previsibilidad ${ }^{62}$. Junto a ello, más previsible y estable que el anterior criterio, el legislador europeo dispone que el criterio de la «nacionalidad» tendrá la consideración de una "cuestión previa», que habrá de ser concretada por la normativa estatal correspondiente - así como respetando los principios generales de la UE- ${ }^{63}$.

13. El art. 22 de los Reglamentos se ocupa, además, de los aspectos temporales que rodean a la designatio iuris. Algo que se plasma, no solo al respecto del momento en que se vaya a poder llevar a cabo esta elección, sino también en relación con la concreción del momento de la conexión de los criterios que utiliza. Por lo que respecta a esta segunda dimensión, por un lado, tanto la residencia habitual, como la nacionalidad, se fijarán temporalmente en el momento en el que se celebre el mencionado acuerdo ${ }^{64}$; mientras que el punto de conexión basado en la creación de la unión registrada, por su parte, se entenderá fijado temporalmente en el momento de su registro ${ }^{65}$.

$\mathrm{Al}$ respecto de la primera perspectiva mencionada, hay que partir del hecho de que la elección de la ley aplicable a los efectos patrimoniales de la pareja podrá llevarse a cabo, tanto con anterioridad a la celebración del matrimonio (o creación de la unión registrada), como en el momento en el que se celebre, e incluso se podrá modificar con posterioridad a este momento ${ }^{66}$. Un acuerdo que, en todo caso, habrá de manifestarse de forma expresa, con el fin de garantizar la seguridad jurídica para este tipo de transacciones ${ }^{67}$. En este sentido, el precepto permite (en su apdo. 1) tanto a los cónyuges como

60 Coester-Waltuen, D., op. cit., p. 202.

${ }^{61}$ La cual se refiere a la localización de elementos como: la celebración del matrimonio, el trabajo o la contribución a la seguridad social, la escolarización de los hijos, la tenencia de préstamos o de propiedades inmuebles, el permiso de conducir, la recepción de correo bancario, la existencia de relaciones personales o administrativas o la necesidad de presencia física. La decisión más reciente, al respecto, es la STJUE de 17 de octubre de 2018, en el asunto C393/18 PPU, UD y XB (ECLI:EU:C:2018:835). Véase la base de datos jurisprudencial elaborada en el marco del proyecto europeo «EUFAM'S» JUST/2014/ JCOO/AG/CIVI/7729 (accesible en http://www.eufams.unimi.it/2017/09/26). Por lo que respecta a la práctica española en su concreción para los supuestos analizados, Diago Diago, P., Pactos o capitulaciones..., op. cit., pp. 287-291.

${ }^{62}$ AÑoveros Terradas, B., «Autonomía de la voluntad...», op. cit., p. 264; DamascelLI, D., «La legge applicabile...», op. cit., pp. 1137-1138.

63 Quinzá Redondo, P., Régimen económico matrimonial, op. cit., p. 367. Considerandos 50 del Reglamento 2016/1103, y 49 del Reglamento 2016/1104. Una remisión a la ley nacional común que difiere de la aproximación más detallada presente en el art. 15 del Convenio de La Haya de 1978.

${ }_{64}$ Sobre su justificación, JAYME, E., op. cit., p. 163. También el art. 3 del Convenio de La Haya de 1978.

${ }_{65}$ Esta localización no se encuentra exenta de problemas en supuestos de registros sucesivos, como destaca Rodríguez Pineau, E., «Los efectos patrimoniales...», op. cit., pp. 949-950 y 954.

66 Esto es, «en todo momento», como menciona el considerando 44 del Reglamento 2016/1103. PÉroz, H., op. cit., p. 35.

67 Considerandos 46 del Reglamento 2016/1003, y 45 del Reglamento 2016/1104. FernáNDEZ RoZAS, J. C., op. cit., p. 12. 
a los futuros cónyuges (o, en su caso, los miembros de la unión registrada) llevar a cabo esta designación de común acuerdo. Así como se les autoriza igualmente a cambiar esta ley en cualquier momento, resultando, por tanto, mutable a voluntad de las partes.

No obstante, y en virtud de lo dispuesto en su apdo. 2, este cambio únicamente surtirá efectos ex nunc. Una irretroactividad que responde al interés de no modificar el régimen legal regulador de determinados bienes adquiridos con anterioridad, aunque puede generar dificultades en la determinación de la regulación de los mismos en un momento posterior, como sería el fraccionamiento que se originaría cuando se planteara la liquidación o disolución del régimen patrimonial propio de la pareja ${ }^{68}$. Por lo que, en principio, resulta lógica su incorporación, salvo pacto en contrario que permita su retroactividad $^{69}$. Una eventual retroactividad que privilegia la voluntad de las partes, y que, en todo caso y como se establece en su apdo. 3, no podrá perjudicar a los derechos de los terceros ${ }^{70}$.

\subsection{La validez material y formal de la elección de ley aplicable y de las capitulaciones matrimoniales}

14. Con un objetivo claramente tuitivo, así como con el fin de que las partes puedan adoptar una decisión informada y plenamente consciente de las consecuencias que se derivan del juego de la autonomía de la voluntad en este ámbito, los Reglamentos requieren que la electio iuris cumpla con las exigencias formales previstas en determinados ordenamientos estatales que se ven conectados con la relación ${ }^{71}$. Unos requisitos que se establecen, casi de forma idéntica, para garantizar la validez formal tanto del acuerdo de ley aplicable en su art. 23, como de las capitulaciones matrimoniales (o de la unión registrada) en su art. 25.

Así, como fórmula de inicio, en su apdo. 1 se incluye una norma de carácter material que contempla la necesidad de que el acuerdo de elección de ley y el relativo a la capitulación se expresen por escrito, con fecha y firmado por ambas partes ${ }^{72}$. A este respecto, como resulta habitual en los instrumen-

68 Un resultado, que, además de resultar contrario al principio de unidad de la ley aplicable que promulga el art. 21, puede generar imprevisibilidad. QuinZÁ REDONDO, P., «La unificación —fragmentada-...», op. cit., pp. 205-206.

69 DutTA, A., "Das neue...», op. cit., p. 1981.

${ }^{70}$ Favoreciendo el buen funcionamiento del tráfico jurídico. AÑoveros Terradas, B., «Autonomía de la voluntad...», op. cit., p. 266.

71 Martiny, D., op. cit., pp. 19-20. Considerandos 47 y 48 del Reglamento 2016/1003, así como 46 y 47 del Reglamento 2016/1104. Con una clara inspiración en el art. 7 del Reglamento 1259/2010, aunque mostrando alguna disparidad que podría suscitar problemas de coordinación. CAMPUZANO Díaz, B., «The coordination of the Regulations on divorce and legal separation with the proposal on matrimonial property regimes», YbPIL, 2011, núm. 13, pp. 233-253, esp. p. 248. Sin embargo, WAUTELET, P., op. cit., pp. 228-229.

${ }^{72}$ Una exigencia también presente en los arts. 19.2 y 20.2 de la Propuesta de Reglamento en materia de régimen económico matrimonial de 2011, así como en los arts. 12 y 13 del Convenio de La Haya de 1978. 
tos europeos elaborados en el marco de la cooperación judicial en materia civil, se dispone la equivalencia de la forma escrita a «toda comunicación efectuada por medios electrónicos que proporcione un registro duradero del acuerdo ${ }^{73}$. Ahora bien, debido a la insuficiencia de tal exigencia mínima, se establece que dichos acuerdos habrán de respetar asimismo las exigencias formales presentes en algunos ordenamientos estatales conectados, para atribuirles validez formal, con la finalidad de incrementar las exigencias formales de los acuerdos y capitulaciones ${ }^{74}$. Unos requisitos que, por su complejidad, pueden dificultar el ejercicio de la designatio iuris ${ }^{75}$.

En primer lugar, caso de que la ley del Estado miembro donde ambos residan habitualmente cuando celebraron tal acuerdo estableciera requisitos formales para las capitulaciones, tales exigencias habrán de ser respetadas —en virtud del art. 23.2 para los acuerdos de ley aplicable y art. 25.2.I al respecto de las capitulaciones-. Además, en segundo lugar, si las partes residieran en distintos Estados miembros en el momento de su celebración, el acuerdo habrá de respetar los requisitos presentes en uno de tales ordenamientos al menos - como establecen, para los acuerdos de ley, los arts. 23.3 y el 25.2.II para las capitulaciones-. Por último, en tercer lugar, cuando únicamente una de las partes tuviera su residencia habitual en un Estado miembro cuando se celebró el acuerdo, los requerimientos formales de dicha ley serán de aplicación -así, el art. 23.4 para los acuerdos de elección de ley y el art. 25.2.III para las capitulaciones-. Asimismo, aunque solamente al respecto de las capitulaciones, habrán de respetarse igualmente las exigencias formales adicionales presentes en la ley aplicable a los efectos patrimoniales.

15. En otro orden de ideas, los Reglamentos 2016/1103 y 2016/1104 contemplan soluciones relativas al consentimiento y a la validez material, aunque exclusivamente al respecto del acuerdo de elección de ley aplicable (esto es, sin referirse a las capitulaciones matrimoniales). En esta línea, el art. 24.1 establece que estos extremos se ordenarán de conformidad con la ley estatal presuntamente elegida por las partes, siempre que tal acuerdo fuera válido ${ }^{76}$. Por último, con el fin de garantizar que el consentimiento de las partes hubiera sido válido, el art. 24.2 autoriza a la parte que alegara que no hubiera prestado su consentimiento, a que invoque la ley del país donde resida habitualmente en el momento en el que se presente la demanda, cuando de las circunstancias se derivara que no resulte razonable acudir a la ley elegida por ambos.

73 Una forma que va resultar poco habitual para las relaciones familiares. DAMASCELLI, D., «La legge applicabile...», op. cit., p. 1142.

74 BARRIÈre BrousSe, I., "Le patrimoine des couples internationaux dans l'espace judiciaire européen», JDI, 2017, núm. 2, pp. 485-514, esp. p. 497; LAGARDE, P., op. cit., p. 682. Aunque sin tener en cuenta los requisitos establecidos por la normativa terceros Estados (al referirse únicamente a los Estados miembros), pudiendo suscitar problemas posteriores de su reconocimiento. VINAIXA MiQuEL, M., op. cit., p. 293.

75 MARINO, S., op. cit., p. 278.

76 También, art. 10 del Convenio de La Haya de 1978. 


\section{LEY APLICABLE EN DEFECTO DE ELECCIÓN}

16. En ausencia de electio iuris - algo que incluiría los supuestos en los que las partes hubieran hecho uso de su autonomía de la voluntad material en sus capitulaciones, pero no de la conflictual — ${ }^{77}$, habrá que acudir a lo establecido en el art. 26. Aunque, eso sí, la formulación de este precepto es bien distinta en los instrumentos analizados, resultando conveniente diferenciar entre uno y otro en esta sede. Así, al respecto del Reglamento 2016/1103, el apdo. 1 del citado precepto contempla que, en ausencia de elección por los cónyuges, resultará aplicable — de forma jerarquizada o en cascada- la ley del país: de su primera residencia habitual tras la celebración del matrimonio, de su nacionalidad común, fijada en el momento de su celebración o, a falta de las anteriores, aquella con la que ambos cónyuges mantengan una conexión más estrecha, igualmente cuando se celebró el mismo.

En este sentido, el legislador europeo ofrece una respuesta que, como en el caso de darse una elección de la ley aplicable, pivota nuevamente entre la residencia habitual y la nacionalidad de los cónyuges (común, en ambos casos), aunque en este caso priorizando el criterio integrador frente al correspondiente al de su identidad cultural - a partir de la expresión jerarquizada del precepto- ${ }^{78}$. Una aproximación que resulta tradicional en este ámbito, basada en los objetivos de previsibilidad y seguridad jurídica - considerando 49-, plenamente coherente con la ofrecida por otros textos de origen internacional. No obstante, puede suscitar problemas de coordinación con otros instrumentos europeos, como los Reglamentos 1259/2010 y 650/2012 - poniendo en valor el valor coordinador de la electio iuris- ${ }^{79}$.

Sobre la delimitación de lo que se ha de entender por el elemento «residencia habitual», nada que añadir a lo expuesto en el apartado anterior. Sobre el criterio de la «nacionalidad», por su parte, recordar su tratamiento como una cuestión previa, a delimitar de conformidad con la normativa del Estado correspondiente. Aunque esta lógica concreción estatal, no debería tener efecto alguno en la determinación de la ley aplicable ${ }^{80}$. Por último, cabe destacar como, en atención a lo previsto en el art. 26.2, en los supuestos de múltiple nacionalidad común de los cónyuges en el momento de la celebración del matrimonio, decaerá este criterio personal - para evitar efectos discriminatorios-, en favor de los criterios contemplados en las letras a) y c) del numeral anterior ${ }^{81}$.

77 Quinzá Redondo, P., «La unificación —fragmentada-...», op. cit., p. 207.

78 Considerando 49. En términos similares, art. 4 del Convenio de La Haya de 1978. Véase JAYME, E., op. cit., pp. 170-171 y 206. La residencia habitual común, a juicio de MARTINY (op. cit., p. 22), se predica del país donde esta se localiza y no de la población donde se encuentra, en concreto.

79 Campuzano Díaz, B., op. cit., pp. 249-250; Quinzá Redondo, P. y GraY, J., op. cit., pp. 533-534 y 539-540.

${ }^{80}$ Considerandos 50 del Reglamento 2016/1103, y 49 del Reglamento 2016/1104.

81 Y ello, con independencia de que solo una de ellas opera de forma efectiva. CoEsTER-WALTJEN, D., op. cit., pp. 204-205. También el art. 15 in fine del Convenio de La Haya de 1978. Una postura que, de 
17. Tan solo cuando no se pueda acudir a los ordenamientos antes señalados, el art. 26.1, letra $c$ ) prevé una solución de cierre basada en el "principio de proximidad», que permite recurrir al ordenamiento con el que mantengan una conexión más estrecha las partes —en atención a todas las circunstancias que existan en el momento de la celebración del matrimonio- ${ }^{82}$. Una conexión criticable, desde la perspectiva de su aplicación práctica, tanto por su ubicación en el precepto y concreción temporal ${ }^{83}$, como por su formulación amplia, por poder generar una cierta incertidumbre $^{84}$. Por contra, además de la adaptación a las circunstancias del caso que permitiría esta conexión flexible, favorecería la coincidencia entre fórum y ius ${ }^{85}$. En relación con ello, y para su concreción -necesariamente autónoma-, se podrían tomar en consideración elementos como: el lugar de celebración del matrimonio ${ }^{86}$, la nacionalidad o la residencia habitual de las partes — singularmente, de forma previa a la celebración- ${ }^{87}$, así como su origen, lengua, cultura o religión ${ }^{88}$, la situación de los bienes de la familia ${ }^{89}$, o incluso donde se localice el cumplimiento y la planificación de los deberes o de las obligaciones inherentes al matrimonio ${ }^{90} \mathrm{o}$ incluso donde se disolvió el matrimonio ${ }^{91}$.

18. Como en el supuesto de la elección de la ley por los cónyuges, también los elementos temporales poseen una singular importancia a la hora de la determinación del ordenamiento rector de la relación en ausencia de electio iuris. Por un lado, el criterio de la residencia habitual se refiere expresamente a la primera que los cónyuges tuvieran, así como esta se fijará tras la celebración del matrimonio. En ambos casos, por tanto, se concreta el momento de la conexión para evitar conflictos móviles, tomando en consideración este primer momento -teniendo pues que esperar a que se produzca este hecho, para que entre en funcionamiento-, con exclusión de los cambios posteriores que se produjeran

algún modo, se alinea con la adoptada por el TJUE al respecto de la determinación de la jurisdicción competente, al respecto del Reglamento 2201/2003 (señaladamente, su Sentencia de 16 de julio de 2009, en el asunto C-168/08, Hadadi, ECLI:EU:C:2009:474), al no contemplar la prevalencia de una nacionalidad sobre la otra. CAmpuZano Díaz, B., op. cit., p. 251; Marino, S., op. cit., p. 280.

${ }_{82}$ Considerando 49. Una conexión empleada igualmente en el art. 4 in fine del Convenio de La Haya de 1978

${ }^{83}$ Rodríguez Benot, A., «La armonización...», op. cit., pp. 568-569. Precisamente por ello, las posibilidades de que se acuda a esta solución de cierre resultan limitadas en la práctica. MARINO, S., op. cit., p. 281; QuinzÁ REDONDO, P. y GraY. J., op. cit., p. 532.

${ }^{84}$ Damascelli, D., «La legge applicabile...», op. cit., p. 1138. Chocando así con conexiones de cierre, más sencillas de aplicar y previsibles, como la lex fori, que favorece el art. 8.d) del Reglamento $1259 / 2010$.

${ }^{85}$ Marino, S., op. cit., p. 282.

${ }^{86}$ Viarengo, I., "The EU Proposal...», op. cit., p. 212. A este elemento ya hizo mención expresa el art. 17.1.c) de la Propuesta de Reglamento en materia de régimen económico matrimonial de 2011.

${ }^{87}$ De este modo, QuinzÁ REDONDo, P., «La unificación -fragmentada-...», op. cit., p. 210.

${ }^{88}$ Coester-Waltjen, D., op. cit., p. 206; Martiny, D., op. cit., p. 23.

${ }^{89}$ PÉroz, H., op. cit., p. 37.

90 DutTA, A., «Das neue...», op. cit., p. 1982; VISMARA, F., «Legge applicabile in mancanza di scelta e clausola di eccezione nel regolamento (UE) N. 2016/1103 in materia di regimi patrimoniali tra i coniugi», Riv. dir. int. pr. proc., 2017, núm. 2, pp. 356-371, esp. p. 363.

${ }^{91}$ MARTINY, D., op. cit., p. 23. 
al respecto de su residencia habitual ${ }^{92}$. Asimismo, esta localización temporal y como se verá más adelante, puede correr el riesgo de que no mantenga una conexión significativa con la relación cuando se suscitara una eventual controversia entre las partes ${ }^{93}$. Sin embargo, por otro lado, tanto la nacionalidad común de los cónyuges, como la normativa más estrechamente vinculada, se localizará temporalmente en el momento de la celebración del matrimonio.

19. La respuesta conflictual que se acaba de presentar para la regulación del régimen económico matrimonial, en defecto de elección de la ley aplicable, resulta bien distinta a la consagrada en el art. 26.1 del Reglamento 2016/1004, para las uniones registradas. En atención a su tenor, en defecto de electio iuris, los efectos patrimoniales se regirán por lo previsto en el ordenamiento del país conforme a cuya ley se hubiera creado la unión registrada. Una opción que conduciría, en la mayoría de ocasiones, a la aplicación de la ley donde se produjo su registro y se confundiría con la lex loci actus ${ }^{94}$. Este criterio de conexión ha de ser bien recibido, debido a que persigue favorecer la previsibilidad y seguridad jurídica, así como por servir al objetivo de garantizar la eficacia de dicha relación, y tratarse de un ordenamiento estatal directamente vinculado con la unión registrada ${ }^{95}$.

20. Por su parte, el art. 26.3 incluye una peculiar «cláusula de escape», de lógica aplicación excepcional ${ }^{96}$ - y con la evidente voluntad de atender a las consecuencias de un eventual conflicto móvil- ${ }^{97}$, con la que se procura cohonestar las posturas de los partidarios de la mutabilidad y aquellos favorables a la inmutabilidad de la lex lausae ${ }^{98}$. Así las cosas, y en atención de determinadas circunstancias de aplicación cumulativa, por medio de la misma cabrá la posibilidad de excluir las soluciones antes expuestas - aunque en el caso del régimen económico matrimonial, exclusivamente en relación con la primera residencia habitual común tras la celebración del matrimonio y no al respecto de la nacionalidad-. En todo caso, esta medida únicamente podrá adoptarse por la autoridad judicial competente y siempre a instancia de una de las partes —no pudiendo actuar pues de oficio el juez- ${ }^{99}$.

92 DutTa, A., «Das neue...», op. cit., pp. 1981-1982; MARINo, S., op. cit., p. 280; PÉroz, H., op. cit., p. 37. Los riesgos que suscita el conflicto móvil vinculado a la residencia habitual en este ámbito fueron denunciados por GonZÁlez BeILfuss, C., "Relaciones e interacciones entre Derecho comunitario, Derecho Internacional privado y Derecho de familia europeo en la construcción de un espacio judicial común», AEDIPr, t. IV, 2004, pp. 117-186, esp. p. 169.

93 Quinzá Redondo, P., «La unificación —fragmentada_...», op. cit., p. 208. Esta localización, a su vez, difiere de la existente en otros Reglamentos, como el 650/2012, que se refiere al momento del fallecimiento, pudiendo generar su descoordinación. Así, BonOMI, A., op. cit., p. 228.

94 MARINO, S., op. cit., pp. 281-282.

95 BARrière Brousse, I., op. cit., pp. 503-504. Considerando 48 del Reglamento 2016/1104.

96 Sobre sus características y diferencias, con respecto a otras manifestaciones más habituales de este tipo de cláusulas, VISMARA, F., op. cit., pp. 363-366.

97 Barrière Brousse, I., op. cit., p. 499. Sobre los precedentes, motivaciones y objetivos de este apartado, QuinzÁ REDONDO, P., «La “cláusula de excepción”...», op. cit., pp. 306-309.

98 Coester-Waltuen, D., op. cit., p. 206.

99 Ibid., p. 207; Damascelli, D., "La legge applicabile...», op. cit., pp. 1139-1140; Lagarde, P., op. cit., p. 683. Considerandos 51 del Reglamento 2016/1103, y 52 del Reglamento 2016/1104. Mientras 
Así las cosas, como reza su párr. I, únicamente se podrá poner en marcha tal exclusión - a modo de una lex non-conveniens - cuando se manifiesten determinadas circunstancias de forma cumulativa que garantizan la conexión ${ }^{100}$. Por un lado, desde una perspectiva objetiva, cuando las partes hubieran contado con una última residencia habitual en otro Estado, siempre que el periodo de esta nueva residencia habitual hubiera sido más largo que en el previo («considerablemente» y comparando el número de años para los matrimonios, así como "significativamente» y en términos absolutos en el supuesto de las uniones registradas), así como — desde una dimensión subjetiva- siempre que estos sujetos hubieran organizado o planificado sus relaciones patrimoniales en función de este ordenamiento posterior ${ }^{101}$.

El criterio temporal se constituye así, en un elemento esencial en la mecánica de la cláusula, que permite atender al «principio de proximidad» para acudir a un ordenamiento más conectado con la relación. El cual, salvo que se pueda llegar a objetivar por medio de un acto de disposición o similar, puede suscitar problemas de determinación y resultar imprevisible en su aplicación práctica ${ }^{102}$. Por su parte, a esta condición temporal se unirá, en el caso de las uniones registradas, la exigencia de que este nuevo ordenamiento atribuya efectos patrimoniales a la relación, para así garantizar su eficacia.

La aplicación de esta ley resultará efectiva (como se concreta en su párr. II) desde el mismo momento del inicio de la relación (ya fuera la celebración del matrimonio o la creación de la unión registrada). Claro está, siempre que ambos sujetos estén conformes con esta fijación temporal de los efectos que vaya a tener este nuevo ordenamiento - planteándose nuevamente problemas de concreción, si surgen desavenencias- ${ }^{103}$. En caso contrario, el momento a tomar en cuenta para determinar los efectos que podrá desplegar este otro ordenamiento, será el del establecimiento de esta última residencia habitual.

Esta solución judicial excepcional contará con una limitación y con una exclusión, como se aprecia de la lectura del art. 26.3.III. Por un lado, la aplicación de la ley de la última residencia común de las partes no podrá afectar a los derechos de terceros que derivaran del juego de la ley fijada en el apdo. 1 (esto es, el de la primera residencia común del matrimonio o donde se creó la unión registrada). Por otro lado, la solución excepcional prevista en este apartado no podrá resultar de aplicación cuando las partes hubieran celebra-

que la mención al «demandante» se entenderá hecha al «solicitante», la autoridad judicial solo podrá excluir la aplicación del apdo. 1.a) en favor de la ley de la última residencia habitual, como aclara QUINZÁ REDONDO, P., «La "cláusula de excepción"...», op. cit., p. 310.

100 Coester-Waltjen, D., op. cit., p. 208; Marino, S., op. cit., p. 282.

101 Barrière Brousse, I., op. cit., p. 499. Crítico por su amplia formulación, MartinY, D., op. cit., p. 24.

102 Péroz, H., op. cit., p. 37; QuinzÁ Redondo, P., «La unificación —fragmentada-...», op. cit., p. 209; VISMARA, F., op. cit., pp. 366-369.

103 Coester-Waltjen, D., op. cit., p. 208; Damascelli, D., «La legge applicabile...», op. cit., p. 1139; QuinŹ́ ReDondo, P., «La "cláusula de excepción”...», op. cit., pp. 310-311. Una expresión de voluntad que incluso podría estimarse como una elección tácita de dicho ordenamiento, a pesar de lo expresado sobre este expediente con anterioridad. 
do capitulaciones, de forma previa a que se estableciera su última residencia habitual común.

\section{4. ÁMBITO DE LA LEY RECTORA Y TUTELA DE LOS INTERESES DE TERCEROS}

21. La lex causae está llamada a cubrir una significativa cantidad de cuestiones, como se deriva del tenor del art. 27. En este sentido, la ley rectora de los efectos patrimoniales de la pareja abarcará - aunque sin constituir un $n u$ merus clausus - ${ }^{104}$ extremos como son: la clasificación de los bienes de uno o ambos miembros de la pareja y vigencia tras la disolución de la relación $a$ ); la transferencia de los mismos de una categoría a otra $b$ ); la responsabilidad de uno de los cónyuges (o miembro de la unión registrada) por las obligaciones y deudas del otro $c$ ); las facultades, derechos y obligaciones de cualquiera de los miembros de la pareja —o de ambos- $d$ ); la disolución de la relación patrimonial, así como el reparto, distribución o liquidación de este régimen e); los efectos patrimoniales sobre la relación entre uno de los cónyuges (o miembro de la unión registrada) y un tercero f); así como la validez material de las capitulaciones $g$ ).

Un listado que establece los límites de la lex causae -incluyendo los conocidos como regímenes económicos primario y secundario- ${ }^{105}$, que se refiere a señaladas materias, tanto relacionadas con el día a día de la relación mientras esta se encuentra vigente - así sus letras a) a d) —, como aquellas que pudieran originarse con motivo de la finalización de la relación —así las letras $a$ ) in fine y la $e$ )— ${ }^{106}$; así como sus efectos frente a terceros - que se analizará seguidamente-, o incluso extremos de la transcendencia de la validez material de las capitulaciones — toda vez que la regulación de su validez formal cuenta con una solución conflictual específica, como ya se ha expuesto-.

22. La protección de los intereses de los terceros constituye una constante en los Reglamentos 2016/1103 y 2016/1104, en consonancia con la importancia que posee esta cuestión en la normativa sustantiva y la publicidad registral del régimen patrimonial de la pareja ${ }^{107}$. Por lo que esta preocupación ha de ser bienvenida y más al respecto de nuestro ordenamiento, donde no se contemplaba una previsión conflictual al respecto ${ }^{108}$. En este sentido y a modo de ejemplo, ya vimos al analizar el art. 22.3, que la elección de ley y

104 Y ello, al disponer que regulará «entre otras cosas».

105 AÑoveros Terradas, B., «Autonomía de la voluntad...», op. cit., p. 252.

106 Quinzá Redondo, P., «La unificación —fragmentada-...», op. cit., pp. 203-204.

107 Véase Diago Diago, P., «La publicidad del régimen matrimonial y la protección de terceros en Derecho Internacional privado español», BIMJ, 2008, núms. 2067 y 2068, pp. 2736-2787; QUINZÁ REDONDO, P., «Inscripción en el Registro de la Propiedad de una escritura de compraventa bajo régimen económico-matrimonial extranjero: La RDGRN de 10 de mayo de 2017», Bitácora Millennium DIPr (accesible en http://www.millenniumdipr.com).

108 Diago Diago, P., Pactos o capitulaciones matrimoniales..., op. cit., pp. 393-398. 
sus eventuales modificaciones retroactivas no podía perjudicar los intereses de los mismos. A su vez, el art. 27 —en su letra f) — contempla que esta materia se encontrará cubierta por la ley rectora de la relación. Sin embargo, el art. 28 dispone de una excepción a este principio que ha de ser valorada de forma positiva en línea de principio ${ }^{109}$, al haberse incorporado con el fin de tutelar los intereses de tales sujetos, en relación con aquellos supuestos en que el tercero debía o habría de conocer la ley rectora del régimen económico matrimonial (o, en su caso, de los efectos patrimoniales de la unión registrada).

En virtud de lo dispuesto en el art. 28.1, uno de los miembros de la relación no podrá invocar la lex causae frente a un tercero, en el marco de un litigio entre uno de los miembros de la pareja - o uno de ellos- y un tercero, salvo que este tercero conociera dicho ordenamiento o hubiera actuado de forma diligente («actuando con la debida diligencia») para su conocimiento. En relación con ello, en su numeral 2 se consigna que se presumirá que conoce la ley rectora de los efectos patrimoniales, en dos situaciones particulares en las que se estimará que resultarán fácilmente predecibles para este sujeto ${ }^{110}$. Por razón de la primera [letra $a$ )], siempre que dicha ley fuera - con carácter alternativo- el ordenamiento que regula la transacción con el tercero (pudiendo dar entrada a la lex contractus), aquel donde el cónyuge (o miembro de la unión registrada) y el tercero residan habitualmente, o de la situación de los inmuebles en su caso. Por su parte, también se alcanzará la misma conclusión [letra $b$ )], cuando cualquiera de los miembros de la unión registrada o matrimonio hubiera cumplido los requisitos de publicidad que se previeran en cualquiera de las leyes estatales antes reseñadas en la letra anterior -igualmente con una naturaleza alternativa-.

En todo caso y según lo establecido en su apdo. 3, cuando la lex causae no pudiera ser invocada según lo previsto en el primer numeral — dado que nos situaríamos en lo establecido en el apdo. 2 de este precepto- ${ }^{111}$, los efectos patrimoniales de la relación se ordenarán de conformidad con lo dispuesto en -de nuevo, con un carácter alternativo-, o bien la ley rectora de la transacción que vincula a uno de los miembros de la pareja con el tercero, o bien la ley de situación del inmueble o donde se registró este bien, según fuera el caso.

\section{NORMAS DE APLICACIÓN}

23. Como resulta habitual en los instrumentos europeos por medio de los que se ofrecen soluciones conflictuales uniformes, los Reglamentos

\footnotetext{
109 Lagarde, P., op. cit., p. 684. No obstante, Barrière Brousse, I., op. cit., p. 505.

110 QuinZÁ REDONDo, P., «La unificación — fragmentada-...», op. cit., p. 215. Acerca de la naturaleza de esta presunción —-también entendida por algunos como una ficción legal—, DAMASCELLI, D., «La legge applicabile...», op. cit., p. 1144; DutTA, A., «Das neue...», op. cit., p. 1983; PÉroz, H., op. cit., p. 39.

111 Quinzá Redondo, P., «La unificación —fragmentada-...», op. cit., p. 216.
} 
2016/1103 y 2016/1104 contemplan una serie de preceptos en los que se atiende a los problemas de aplicación que pudieran tener lugar. A pesar de que tales respuestas no destacan por su gran originalidad, al respecto de los Reglamentos europeos que constituyen sus precedentes, resulta apropiado hacer mención de las soluciones incorporadas en los instrumentos analizados, al igual que las peculiaridades que presentan en este ámbito.

\subsection{Adaptación de los derechos reales, leyes de policía, orden público y exclusión del reenvío}

24. Para empezar, el art. 29 establece la posibilidad de que los derechos reales presentes en la lex causae y que fueran invocados por su titular en un Estado miembro cuya ley no contemple los mismos, se adapten a otro derecho real existente en el mismo (generalmente la lex fori) que, a su vez, fuera cercano y equivalente al mismo. Y ello, como clarifica el considerando 25 , con el objetivo de que los cónyuges - o miembros de la unión registrada- puedan disfrutar de los derechos que les han sido transmitidos o creado en otro Estado miembro. La posibilidad de adaptación de los derechos reales no se encontraba presente en las Propuestas de Reglamento de 2011, aunque no resulta una posibilidad totalmente novedosa para el legislador europeo - encontrando su inspiración en el art. 31 del Reglamento 650/2012-112.

Este precepto establece, asimismo, el modo y las condiciones en las que se llevará a cabo tal adaptación de los derechos reales. Por un lado, esta actividad tendrá lugar solamente cuando ello resultara necesario y siempre en la medida de lo posible ${ }^{113}$. Por lo que ambas circunstancias habrán de ser sopesadas de forma previa. De otro lado, para poner en práctica la eventual adaptación del derecho real se habrán de considerar, tanto los objetivos e intereses que busque el derecho en cuestión, como los efectos que del mismo se deriven.

25. La aplicación del ordenamiento del foro también tendrá cabida al respecto de dos situaciones ya tradicionales en los instrumentos europeos con normas de conflicto de leyes y que implican una limitación al juego de la lex causae. Esto es, cuando se contemple la aplicación de las leyes de policía del foro - prevista en su art. 30 - o si hubiera que acudirse a la excepción de orden público - recogida en el art. 31-. Por lo que respeta a la segunda posibilidad, la redacción del precepto no muestra novedad alguna frente a Reglamentos previos, contemplándose el juego de la lex fori de forma restrictiva y

112 Rodríguez Sánchez, J. S., "Artículo 31. Adaptación de los derechos reales», en IgLESIAS BuHIgues, J. L. y Palao Moreno, G. (dirs.), op. cit., pp. 259-267.

113 Sobre este extremo, cabrá recibir información de las autoridades de otros Estados miembros para recibir información sobre el contenido y alcance de tales derechos reales (considerando 25), pudiendo llevarse a cabo formas diferentes de adaptación a las previstas en los Reglamentos, cuando de forma explícita no se conocieran tales derechos reales (considerando 26). 
excepcional cuando la aplicación del ordenamiento foráneo resultara manifiestamente incompatible con el orden público del mismo ${ }^{114}$.

Una excepción que, por ejemplo, permitirá a los Estados miembros mantener su concepción sobre cuestiones espinosas en la UE como la de las uniones entre personas del mismo sexo o la recepción de instituciones foráneas que ocasiones una discriminación por motivos de género ${ }^{115}$, aunque habrá de ser interpretada a la luz de la Carta de los Derechos fundamentales de la UE, y de forma singular a la luz del principio de no discriminación previsto en su art. $21^{116}$. Su aplicación práctica podría conducir, a modo de ejemplo, a la exclusión de aquellas disposiciones foráneas que generaran una discriminación por razón de nacionalidad o de sexo, al igual que las vulneraran los deberes y derechos de contenido patrimonial que se impusieran con carácter general en el ordenamiento del foro ${ }^{117}$.

26. En relación con la aplicación de las leyes imperativas del foro — una auténtica novedad al respecto del DIPr de familia y sucesiones UE- ${ }^{118}$, el art. 30.2 delimita este concepto haciendo referencia a aquellas disposiciones del ordenamiento del juez competente «cuya observancia considera esencial un Estado miembro para salvaguardar sus intereses públicos», señalando que su juego será prioritario cualquier que sea el ordenamiento estatal rector del régimen económico matrimonial (o de los efectos patrimoniales de la unión registrada) ${ }^{119}$.

En particular — junto a las normas que prevén la solidaridad económica o la contratación vinculada a la gestión del hogar-, cabe destacar, por su importancia práctica, que en esta noción se han de incluir las normas previstas para la protección de la vivienda u hogar familiar ${ }^{120}$; exigiéndose así el consentimiento de la parte de propietario de la misma, para su disposición o gravamen por parte del titular ${ }^{121}$. No obstante, hay que tener presente que el juego de esta excepción al juego de la lex causae, también habrá de contar con una interpretación restrictiva, para no malograr los objetivos que persiguen los Reglamentos ${ }^{122}$.

114 Damascelli, D., «La legge applicabile...», op. cit., p. 1148.

115 Téngase en cuenta el art. 9.

116 Considerandos 54 del Reglamento 2016/1103, y 53 del Reglamento 2016/1104. AÑoveros TERRADAS, B., "Autonomía de la voluntad...», op. cit., p. 270; QuinzÁ REDONDo, P., Régimen económico matrimonial, op. cit., pp. 375-378.

117 Clavel, S. y Jault-Seseke, F., «Public policy considerations - Changes in continuity. Comments on articles 30 and 31 of the Regulations on patrimonial consequences of marriages and registered partnerships», YbPIL, 2017-2018, núm. 19, pp. 234-246, esp. pp. 238-240; QuINZÁ REDONDO, P., «La unificación —fragmentada-...», op. cit., p. 211.

118 Damascelli, D., «La legge applicabile...», op. cit., p. 1149. Una formulación que no prevé la toma en consideración de las disposiciones imperativas de otros Estados conectados con la relación. Clavel, S. y JaUlt-SeSEKe, F., op. cit., pp. 243-246.

119 En particular, el eventual «régimen primario» de la lex fori se impondrá al propio de la lex causae. Añoveros Terradas, B., "Autonomía de la voluntad...», op. cit., p. 270.

120 Considerandos 53 del Reglamento 2016/1103, y 52 del Reglamento 2016/1104. DutTA, A., «Das neue...», op. cit., p. 1983.

121 Quinzá Redondo, P., «La unificación —fragmentada-_..», op. cit., p. 211.

122 Considerandos 53 del Reglamento 2016/1103, y 52 del Reglamento 2016/1104. CARrión García DE PARAdA, P., op. cit., pp. 117-118. 
27. La exclusión del reenvío, establecida en el art. 32, merece un mínimo comentario. La solución propuesta ha de ser recibida, desde un inicio, de forma positiva por su claridad. Sobre todo, al tratarse de una materia donde los intereses de las partes pueden ser contrapuestos y la professio iuris (aun cuando limitada) cuenta con un papel significativo, que podría malograrse por efecto de reenvío ${ }^{123}$. En este sentido, la solución se alinea con la adoptada de modo habitual por el resto de instrumentos europeos en sector de la ley aplicable - por su cercanía, de forma significativa, el art. 11 del Reglamento $1259 / 2010$ - , con el fin de preservar la certeza legal y previsibilidad para las partes.

Por el contrario, esta exclusión no solo plantea ciertos problemas prácticos, sino que igualmente choca con la solución propuesta para el ámbito sucesorio - apartándose en extremo de lo establecido en el art. 34 del Reglamento 650/2012 - ${ }^{124}$. Por lo que, su exclusión en este supuesto, no solo impide una sencilla coordinación entre ambos instrumentos, sino también atender a problemas que pudieran generarse en la práctica —como las que tendrían lugar al respecto de la remisión a normativas donde no se contemplara una ordenación legal de estas relaciones económicas, o evitar decisiones irreconciliables provenientes de terceros Estados- ${ }^{125}$.

\subsection{Conflictos territoriales e interpersonales de leyes}

28. La posibilidad de que la ley estatal reclamada por la norma de conflicto cuente con una naturaleza plurilegislativa (como sucede en el caso español), constituye un lugar común en los Reglamentos europeos que contienen normas de conflicto de leyes. En el caso que nos ocupa, son los arts. 33 a 35 de los Reglamentos 2016/1103 y 2016/1104 los que atienden a esta eventualidad $^{126}$. Estos preceptos se enfrentan, respectivamente, a las situaciones conflictos de leyes de base territorial y de base personal, así como a la no exigencia de acudir a las soluciones previstas en estos Reglamentos en situaciones de plurilegislatividad.

Por lo que respecta a los conocidos como conflictos territoriales de leyes, el legislador europeo ha optado en el art. 33.1 y como solución de partida, por una remisión de tipo indirecto o subsidiario. Esto es, confiando la localización

\footnotetext{
123 Lagarde, P., op. cit., p. 685.

124 Iglesias Buhiges, J. L., "Artículo 34. Reenvío», en Iglesias Buhigues, J. L. y Palao Moreno, G. (dirs.), op. cit., pp. 282-287.

125 Críticos con esta disparidad y su exclusión en todo supuesto -incluso para los supuestos de ausencia de elección-, CARrión García de PARAda, P., op. cit., p. 116; DAMASCelli, D., «La legge applicabile...», op. cit., p. 1136; DutTA, A., "Das neue...», op. cit., p. 1983; LaGARDE, P., op. cit., pp. 684-685; QuinzÁ REDONDo, P., Régimen económico matrimonial, op. cit., pp. 378-379.

126 Considerandos 55 del Reglamento 2016/1103, y 54 del Reglamento 2016/1104. Estos preceptos se alinean con lo establecido en los arts. 36 a 38 del Reglamento 650/2012. Véase el comentario a estos preceptos elaborado por Quinzá Redondo, P., en Iglesias Buhigues, J. L. y Palao Moreno, G. (dirs.), op. cit., pp. 291-307.
} 
de la normativa aplicable - dentro de las distintas unidades territoriales que lo componen - a las soluciones internas para solventar los conflictos de leyes que se prevean en el ordenamiento estatal reclamando. Por tanto, en el caso español, donde coexiste esa plurilegislatividad de base territorial en el ámbito que nos ocupa, esta remisión nos situaría en la aplicación del art. 16.1 CC.

Por su parte, el art. 33.2 regula el supuesto en el que el ordenamiento estatal no contemplara esta normativa. Así las cosas, cuando el punto de conexión nacional fuera a favor de la residencia habitual, se entenderá como la ley de la unidad territorial donde se sitúen la residencia habitual [letra $a$ )]. En el mismo sentido [letra $b$ )], la referencia a la nacionalidad se relacionará con la unidad territorial con la que esta persona mantenga una relación más estrecha. Para el resto de supuestos distintos de los dos anteriores, la letra $c$ ) conduce al juego de la ley de la unidad territorial donde sitúe el elemento en cuestión. Tal y como podría suceder con la mención que se realiza en el art. 28 de la ley de la transacción, de la lex rei sitae para los inmuebles o de la ley de los derechos registrados y la unidad territorial donde estos se localizaran.

29. De otro lado y en relación con los llamados conflictos interpersonales de leyes, el art. 34 (un precepto no incluido en la propuesta de 2011) parte igualmente de una aproximación indirecta, para, con posterioridad y en ausencia de una respuesta ad hoc para la diversidad legislativa de base personal en dicho ordenamiento, establecer que, en tales casos se acudiría al conjunto normativo o régimen legal con el que los cónyuges (o miembros de la unión registrada) mantengan una conexión más estrecha. Esta problemática, sin embargo, no se plantearía para el caso español en su proyección ad intra -al carecer de este tipo de plurilegislatividad-, por lo que resulta ajena a la problemática antes mencionada.

30. La aproximación de tipo indirecto o subsidiario que promulgan los instrumentos analizados ha suscitado (melius, reavivado) un intenso debate en seno de la doctrina española cuando se presenta un conflicto territorial de leyes ad intra ${ }^{127}$. Una controversia fomentada, en este caso, por la inexistencia de normas de conflicto de leyes en materia de efectos patrimoniales de las uniones registradas en España, que completaran la remisión que contiene el art. 16.1 CC —a diferencia de lo que acontece al respecto del régimen económico matrimonial, regulado en los arts. 9.2 y $9.3 \mathrm{CC}$ - En relación con ello y como es sabido, las opciones oscilarían entre promover un juego dinámico de las soluciones conflictuales presentes en los mismo o acudir a una aplicación estática de las mismas ${ }^{128}$.

Según la primera, se propondría acudir a las soluciones previstas en los Reglamentos - en este caso, ante la inexistencia de soluciones internas-.

127 Cebrián Salvat, M. A., op. cit., pp. 138-140; Soto Moya, M., op. cit., pp. 25-29 y 30-31; QuinZÁ REDONDO, P., «La unificación — fragmentada-...», op. cit., pp. 213-214.

128 Véase Quinzá Redondo, P., «La unificación —-fragmentada-...», op. cit., p. 213, con amplias referencias doctrinales en nota 69. 
Entre otros motivos, in casu, debido a que la previsión de no aplicación a la que hace mención el art. 35 estaría concebida tanto como una recomendación - y no como una obligación de no hacerlo-, así como para garantizar la unidad de soluciones en este ámbito. Por el contrario, la preferencia por una aplicación estática conduciría a la necesidad de acudir a las reglas de conflicto previstas en nuestro sistema de DIPr - arts. 9 y ss. CC-, a partir de la remisión literal realizada en el art. 16.1 CC, obligando a tener que diferenciar entre los planos internacional e interregional. La postura estática, sin embargo, y por lo que respecta el caso español, suscita problemas específicos ${ }^{129}$.

Así, junto a la inexistencia de una solución normativa ni jurisprudencial clara, nuestra doctrina mantiene dispares posicionamientos sobre la ley rectora de los efectos patrimoniales de la unión registrada. Los cuales pivotarían entre aquellas que fomentan la aplicación analógica de los arts. 9.2 y 9.3, del art. 9.1, o del $10.5 \mathrm{CC}$, de aquellas fundamentadas en generar una solución específica basada en la ley del registro que se combinaría con la normativa sectorial prevista en la normativa convencional ${ }^{130}$, acudir a soluciones en distintos escalones que pasaría por aplicar la normativa que lo ordene en cada Comunidad Autónoma [en virtud del art. 33.2.c)] ${ }^{131}$, o incluso favorecer el juego supletorio de las soluciones previstas en los Reglamentos - apoyando su aplicación dinámica- ${ }^{132}$. Una laguna que, junto a la disparidad de soluciones propuestas, vienen a reforzar la necesidad de que nuestro legislador estatal se enfrente a las cuestiones que suscitan este tipo de parejas y los efectos patrimoniales que de las mismas se derivan, con el fin de garantizar la certeza y previsibilidad en la materia. Una acción normativa que, en todo caso, habría de tender hacia su normalización y garantizar un tratamiento similar al que se dispensa a los regímenes económicos matrimoniales.

\section{A MODO DE CONCLUSIÓN}

31. Desde el 29 de enero de 2019, resultan de plena aplicación los Reglamentos 2016/1103 y 2016/1104, por los que se establece una cooperación reforzada en los ámbitos de la competencia, la ley aplicable, el reconocimiento y la ejecución de resoluciones en materia de regímenes económicos matrimoniales y en materia de efectos patrimoniales de las uniones registradas. Unos instrumentos que, a pesar de su trascendencia, obligarán únicamente a los dieciocho Estados miembros que participan en la cooperación reforzada; consolidándose esta limitación territorial, como una constante en los más recientes instrumentos europeos en materia de familia. Concebidos como Reglamentos «completos» - al igual que sus precedentes inspiradores-, se

129 Iglesias Buhigues, J. L., «La remisión a la ley española en materia sucesoria y de régimen económico matrimonial», $C D T$, vol. 10, 2018, núm. 1, pp. 233-247, esp. pp. 241-242 (accesible en https://erevistas.uc3m.es/index.php/CDT/article/view/4122).

130 Cebrián Salvat, M. A., op. cit., pp. 138 y 139.

131 Soto Moya, M., op. cit., pp. 30-31.

132 QuinZÁ Redondo, P., «La unificación —fragmentada-...», op. cit., p. 214. 
han analizado únicamente desde la perspectiva de la respuesta conflictual que diseñan.

La aproximación que consagran los Reglamentos europeos para el sector de la ley aplicable constituye una novedad para el DIPr europeo - regido hasta la fecha exclusivamente por normativa de origen estatal-, que, en línea de principio, ha de ser bienvenido. Y ello, no solo por concebir una ordenación uniforme ex novo de los efectos económicos del matrimonio en situaciones transfronterizas en el marco de la UE - aunque contara con importantes precedentes convencionales-, sino también por hacerlo al respecto de un ámbito controvertido - al no contar con una ordenación en todos los Estados miembros-, como el de los efectos patrimoniales de las uniones registradas. En esta línea, los Reglamentos ofrecen un sistema uniforme y de aplicación universal, que atiende a las cuestiones de ley aplicable que pudieran surgir en su ámbito de aplicación, en un contexto de una gran disparidad normativa estatal — sustantiva y conflictual - y una creciente movilidad en el interior de la UE; persiguiendo favorecer la seguridad jurídica y la previsibilidad para los cónyuges (o, en su caso, los miembros de la unión registrada) y los terceros.

Basados en el principio de la unidad de la ley rectora al fondo de las cuestiones que regulan - que puede resultar quebrado, como se ha comprobado-, los Reglamentos ponen el acento en la autonomía de la voluntad conflictual -favoreciendo así su coordinación con otros instrumentos europeos en materia de familia y sucesiones-, que podrá llevarse a cabo en cualquier momento. Aunque recogen de forma limitada por lo que respecta a las leyes susceptibles de ser seleccionadas — de forma alternativa-, incluyendo previsiones que garanticen el consentimiento informado y válido de las partes. Los cuales, en ausencia de una electio iuris expresa, privilegian la aplicación jerarquizada de ley de la residencia habitual de las partes de la relación — tras la celebración del matrimonio o unión, susceptible de sustituirse por la última que poseían en determinadas circunstancias, si así lo estima la autoridad judicial—, que prioriza frente a su nacionalidad común —-facilitando su integración jurídica-, contando con una solución de cierre basada en el principio de proximidad.

Con una gran amplitud, en cuanto a las cuestiones regulables por la lex causae, los Reglamentos ponen un especial acento en una cuestión singularmente problemática, como es la relativa de la protección de los intereses de los terceros y su previsión al respecto de la misma - cuando su comportamiento resultara diligente-. Junto a ello, contienen un amplio aparato normativo para atender los problemas de aplicación de las normas de conflicto de leyes que - como sucede al respecto de otros Reglamentos precedentes, con soluciones muy similares-, aportan un elevado nivel de certeza a los cónyuges (o miembros de la unión registrada) y los terceros.

32. Las bondades que rodean las soluciones previstas en los Reglamentos analizados no impiden, empero, que sean varias las cuestiones que deja abiertas y las dificultades que puede generar su puesta en práctica; poniendo 
en riesgo los objetivos perseguidos, tal y como se ha puesto de manifiesto a lo largo de este estudio. Así, a modo de ejemplo, de un análisis de las condiciones que rodean la electio iuris y su validez formal, se aprecian las incertidumbres y dificultades que pudieran generarse en la práctica. Junto a ello, frente a las posibilidades de coordinación con otros instrumentos europeos que facilita la elección de ley, la respuesta conflictual prevista para los casos de ausencia de tal designación compromete esta coordinación en la práctica. Junto a ello, igualmente pueden suscitar dificultades, la ausencia de una delimitación autónoma y uniforme del criterio de la residencia habitual, el recurso que se hace del «principio de proximidad», o la complejidad de algunas de las soluciones que incorpora. En todo caso, habrá que esperar al momento de su aplicación práctica para comprobar el alcance de estos riesgos, así como confiar en que sirvan efectivamente a los objetivos que les inspiraron y, de modo singular, favorezcan la seguridad jurídica y previsibilidad en la gestión legal de las relaciones económicas de los matrimonios y uniones registradas, que favorezca la movilidad internacional de las personas.

33. No obstante, las dificultades que la aplicación de estos Reglamentos suscita, también se ven fomentados por la inacción de nuestro legislador. Así, la ausencia de una normativa estatal relativa a las uniones registradas (y sus efectos patrimoniales) en España, genera un insoportable nivel de incertidumbre al respecto de cuestiones como la delimitación del ámbito de aplicación material del Reglamento 2016/1104, o la determinación de la ley rectora. Al tratarse de un medio plurilegislativo donde, en a falta de una legislación estatal —ni sustantiva, ni conflictual—, coexisten normas de CCAA sobre uniones no matrimoniales con una distinta naturaleza y alcance. Una compleja situación que tenía que haber previsto a la hora de negociar y vincularnos al procedimiento de cooperación reforzada. En consecuencia, no ya para desterrar la incertidumbre que este silencio genera desde una perspectiva interna, sino para atender a los objetivos que persiguen los Reglamentos, resulta imperativo que el legislador español se enfrente a esta laguna en nuestro ordenamiento.

\section{RESUMEN}

\section{LA DETERMINACIÓN DE LA LEY APLICABLE EN LOS REGLAMENTOS EN MATERIA DE RÉGIMEN ECONÓMICO MATRIMONIAL Y EFECTOS PATRIMONIALES DE LAS UNIONES REGISTRADAS 2016/1103 Y 2016/1104}

Los Reglamentos 2016/1103 y 2014 constituyen un nuevo paso en la construcción de un Derecho internacional privado europeo de familia y sucesiones. Desde la perspectiva de la determinación de la ley aplicable, sus soluciones se ven fuertemente inspiradas en sus precedentes convencionales y europeos, incorporando un nuevo marco normativo uniforme y con efectos erga omnes para los ordenamientos de los Estados miembros que participan en el procedimiento de cooperación reforzada. Los instrumentos favorecen la autonomía de la voluntad en este ámbito, estableciendo soluciones en defecto de esta elección que atienden a los objetivos de seguridad y previsibilidad para las partes y terceros. Su valoración general, aunque positiva, no se encuentra exenta de incertidumbres prácticas, mientras que, 
en el caso español, plantea problemas particulares la inexistencia de una normativa estatal para las uniones registradas.

Palabras clave: régimen económico matrimonial, efectos patrimoniales de las uniones registradas, ley aplicable, Derecho internacional privado, Unión Europea.

\section{ABSTRACT \\ THE LAW APPLICABLE TO MATTERS CONCERNING MATRIMONIAL PROPERTY AND PROPERTY CONSEQUENCES OF REGISTERED PARTNERSHIPS ACCORDING TO EU REGULATIONS 2016/1103 AND 2016/1104}

Regulations 2016/1103 and 2016/1104 involve a new step forward in the development of a European Private International Law in the field of Family and Successions. From the perspective of choice-of-law, their solutions are strongly inspired by their conventional and European precedents, creating a new and uniform legal framework with an erga omnes effect for those Member States participating in the enhance cooperation procedure. Those instruments favour party autonomy, establishing solutions in defect of choice of law, which provide legal certainty and predictability for spouses/partners and third parties. Despite their benefits, from a general perspective, those Regulations are not free of uncertainties, apart from the internal problems which are linked to the lack of a Spanish legal framework for registered partnerships.

Keywords: matrimonial property regimes, property consequences of registered partnerships, applicable law, private international law, European Union. 